\title{
Juventude Rural e as contribuições do Projeto Transformar de Capacitação de Jovens Rurais no sul de minas (2006-2013)
}

\section{Flora Teixeira Castro}

flora.teixeira@emater.mg.gov.br

Universidade Federal de Lavras | Brasil

\section{Resumo}

Um dos grandes desafios do meio rural é a continuidade da produção de alimentos e a formação de uma nova geração de agricultores, à medida que os filhos abandonam a propriedade. 0 propósito deste estudo foi de analisar os resultados do Projeto Transformar de Capacitação de Jovens Rurais, para a permanência dos jovens no campo e na sucessão familiar, no Sul de Minas. A Empresa de Assistência Técnica e Extensão Rural do Estado de Minas Gerais (Emater-MG) executou, no período de 2006 a 2013, o Projeto "TRANSFORMAR", voltado para a Juventude Rural. Buscando a combinação de estudos qualitativos e quantitativos, a análise dos resultados da pesquisa permitiu verificar que grande parte dos jovens rurais do Sul de Minas gosta de morar no campo e pretende dar continuidade à atividade agrícola, mas encontra dificuldades de conciliar trabalho e estudo e obter renda própria. 0 estudo possibilitou conhecer a realidade em que vivem os jovens rurais do Sul de Minas, mostrou que o Projeto Transformar trouxe diversas contribuições para estimular o desenvolvimento e inserção socioeconômica dos jovens rurais e sua permanência no campo e apresentou algumas propostas e reflexões para subsidiar o estabelecimento de novas estratégias de trabalho com a juventude rural.

\section{Palavras-chave}

Juventude rural. Migração. Sucessão familiar. Políticas Públicas. Projeto Transformar. 


\section{Introdução}

Nos estudos analisados sobre juventude rural (BRUMER; PANDOLFO; CORADINI, 2008; CAMARANO; ABRAMOVAY, 1999; CASTRO, 2009; FERRARI et al., 2004; WEISHEIMER, 2005), os temas mais recorrentes são a migração dos jovens, justificada por uma percepção negativa da atividade agrícola, atração para o meio urbano e os problemas da transferência dos estabelecimentos agrícolas familiares à nova geração. São usuais nos estudos as citações de que a migração jovem e feminina tem contribuído para o "envelhecimento" e "masculinização" da população que permanece no campo, o que influencia os rapazes.

De acordo com os autores Mello et al. (2003) e Spanevello et al. (2011), um dos grandes desafios que se coloca para o meio rural é a continuidade da produção, com a formação de uma nova geração de agricultores, à medida que os filhos abandonam a propriedade por não poder ou não querer exercer a profissão de agricultor. 0 meio rural transforma-se em um espaço cada vez mais heterogêneo e desigual, onde a juventude é afetada de maneira mais dramática por essa dinâmica de diluição de fronteiras entre o espaço urbano e rural, associada à falta de perspectivas para quem vive da agricultura. A disposição dos jovens em suceder os pais está associada à própria continuidade da agricultura familiar como um todo.

Há certo consenso nas pesquisas (ABRAMOVAY et al., 2001; BRUMER, 2007; CASTRO, 2005b; FERRARI et al., 2004; SPANEVELLO et al., 2011; WEISHEIMER, 2005) quanto às dificuldades enfrentadas pelos jovens no campo, principalmente, quanto ao acesso à escola e trabalho e a atração do jovem pelo meio urbano. Do ponto de vista político, acadêmico, da pesquisa e da sociedade brasileira, a população jovem esteve durante muito tempo numa situação de invisibilidade e à margem de qualquer política pública. A partir dos anos 1990, as discussões demonstraram a necessidade de atenção especial a esta categoria social, o que foi apontado pelos autores Castro (2005a, 2007, 2009) e Weisheimer (2005). As políticas públicas direcionadas ao campo parecem não atender os anseios e necessidades dos jovens, contribuindo para a inviabilidade de sua permanência no meio rural e esses jovens não se tornam sujeitos de direitos sociais e alvos de políticas públicas.

A população rural em Minas Gerais, na faixa etária de 15 a 29 anos e em 2000, o estado tinha 862.529 jovens rurais, enquanto dez anos depois, registrava 700.826 pessoas, na mesma faixa de idade. A estimativa é de uma população de 120 mil jovens rurais no Sul de Minas, número suficiente para justificar a necessidade de investir em políticas públicas para esse público, com enfoque para as relações de gênero e processos de empoderamento (IBGE, 2010).

A Empresa de Assistência Técnica e Extensão Rural do Estado de Minas Gerais (Emater$\mathrm{MG}$ ), vinculada à Secretaria de Estado de Agricultura, Pecuária e Abastecimento de Minas Gerais, tendo como foco de suas ações a agricultura familiar, trabalha com programas específicos de 
juventude rural desde sua criação como ACAR, em 1948, com o projeto dos Clubes 4-S (até 1986) e a partir de 2006, desenvolveu o Projeto "TRANSFORMAR" (EMATER-MG, 2007).

Com o lema Uma Nova Minas com a Juventude Rural e objetivo de promover a formação crítica, cidadã e profissional de jovens rurais, habilitando-os para a implementação de projetos produtivos com geração de ocupação e renda, valorizando a cultura local, sem comprometimento dos recursos naturais, o Transformar capacitou filhos e filhas de agricultores familiares, na faixa etária de 16 a 29 anos, no período de 2006 a 2013. Como um processo de educação não formal, utilizou o método pedagógico da alternância, com períodos alternados entre construção de conhecimento em aulas teóricas e reflexivas e a vivência de atividades produtivas agrícolas e não agrícolas. Bem como o exercício da participação e gestão social em espaços de tomada de decisão de políticas para o desenvolvimento rural sustentável, dentro da Metodologia Participativa de Extensão Rural para o Desenvolvimento Sustentável-MEXPAR ${ }^{1}$ (EMATER-MG, 2010).

Tendo como eixos norteadores a qualificação profissional, organização social, educação do campo, crédito rural, atividades produtivas, meio ambiente e articulação institucional. Desde que foi implantado em 2006, o projeto capacitou mais de 8 mil jovens no Estado e no Sul de Minas, atendeu mais de mil e quinhentos jovens rurais, em, aproximadamente, 150 municípios. As capacitações realizadas no Sul de Minas aconteceram em vários locais, aliando teoria e prática e priorizando sempre as infraestruturas e professores do Instituto Federal Sul de Minas (Campus Inconfidentes, Machado e Muzambinho) e Universidade Federal de Lavras.

Em 2009, o Instituto Federal, Campus Inconfidentes, em parceria com a EmaterMG/Projeto Transformar, iniciou a Semana do Jovem Agricultor - SEJA com minicursos voltados para jovens agricultores nas diversas áreas da agricultura, priorizando temas como cafeicultura, bovinocultura, olericultura, agroindústria, artesanato, meio ambiente e informática (INSTITUTO FEDERAL DO SUL DE MINAS - IFSULDEMINAS, 2013).

O objetivo central desta pesquisa foi analisar de que forma o Projeto Transformar de capacitação dos jovens rurais contribuiu para oportunizar melhores condições de vida e permanência deles no campo. Também conhecer a realidade em que vivem os jovens rurais do Sul de Minas, seus anseios e perspectivas de futuro e verificar o que modificou na vida dos jovens rurais após terem participado deste projeto: as atividades produtivas que desenvolvem (agrícolas e não agrícolas), as condições de vida e trabalho, as motivações para permanência ou evasão dos jovens do campo, os espaços sociais ocupados pelos jovens rurais.

1 MEXPAR: processo metodológico fundamentado nos princípios da participação, dialogicidade, troca de saberes, planejamento participativo e gestão social. 
A problemática apresentada neste estudo tem forte relação com a trajetória pessoal da pesquisadora como extensionista local da Emater-MG por 23 anos, com experiências na juventude rural (Clubes $4-S)^{2}$ e como coordenadora do Projeto Transformar. Outra fonte de inspiração para a realização desta pesquisa foi o interesse despertado no curso de mestrado profissional de Desenvolvimento Sustentável e Extensão Rural da UFLA, em 2014, fato este que também a instigou a estudar e pesquisar o tema da juventude rural, procurando articular experiência de campo com os conhecimentos proporcionados nas disciplinas do mestrado.

Partindo do resgate dos debates sobre juventude rural, a pesquisa problematiza a questão da migração dos jovens do campo para as cidades e da sucessão familiar; apresenta as políticas públicas para juventude rural, incluindo o trabalho de extensão rural com esta categoria social, referenciando o início do trabalho com os Clubes de Juventude Rural e depois o Projeto Transformar. Descreve-se a área de estudo; o perfil dos jovens sujeitos deste trabalho; os fatores que influenciam a migração ou permanência de jovens rurais no campo e a perspectiva dos jovens rurais. As considerações finais apresentam uma análise dos resultados da pesquisa e propostas que possam subsidiar o estabelecimento de novas estratégias de trabalho com a juventude rural, considerando sua importância relevante para a continuidade da reprodução do espaço rural e da sucessão da agricultura familiar.

\section{Metodologia}

Analisar um projeto de juventude rural significa identificar como se encontram os jovens rurais beneficiados, pela comparação com não beneficiários, verificando qual a influência do projeto no interesse do jovem em permanecer no meio rural ou em migrar para outro local ou para outra atividade. A partir da análise dos trabalhos que serviram de referência, busca-se caracterizar o jovem rural e verificar a situação mapeada nesta pesquisa com jovens rurais, filhos (as) de agricultores familiares, dependente/subordinado do pai, na faixa etária de 16 a 29 anos, com objetivo de conhecer melhor a realidade da juventude rural do Sul de Minas e aprofundar um pouco mais em questões fundamentais para a continuidade dos jovens no campo.

De acordo com Gil (2008), classifica-se esta pesquisa como descritiva, uma vez que procura descrever, por meio de análises da realidade e literatura existente, quais as principais características da juventude rural da região do Sul de Minas.

\subsection{Universo pesquisado: Sul de Minas}

2 Os Clubes 4-S (Saber, Servir, Sentir e Saúde) eram grupos de jovens rurais trabalhados pela extensão rural nas décadas de 50 a 80. 
Juventude rural e as contribuições do Projeto Transformar de capacitação de jovens rurais no sul de minas (2006-2013)

O Sul de Minas é uma das 07 Macrorregiões no Estado definidas para o trabalho da Emater-MG, composta de 153 municípios, com cinco regionais da Emater-MG: Alfenas, Guaxupé, Lavras, Passos e Pouso Alegre e uma população de 2.346 .077 habitantes. 0 principal setor econômico é o agropecuário, com prevalência de $80 \%$ de estabelecimentos da agricultura familiar, correspondendo a 36\% da área e as atividades produtivas são café, pecuária de leite, cana-de-açúcar, milho, feijão e hortifrutigranjeiros, segundo o Plano Safra da Emater-MG.

A definição do local da pesquisa foi influenciada pelo fato de ser o local de trabalho da pesquisadora e por ter sido coordenadora do projeto, durante os oito anos de sua execução, fato de grande importância pelo número de experiências, dados e informações extremamente relevantes para avaliação a eficácia deste programa da Emater-MG.

\subsection{Pesquisa Bibliográfica}

Quanto aos procedimentos adotados na coleta de dados, desenvolveu-se a pesquisa bibliográfica realizada com o levantamento de dados secundários sobre a juventude rural no Brasil para estabelecer um marco teórico, utilizando as palavras chave, buscando estudos, artigos, dissertações, teses do período 2005 a 2012 ou ainda alguns anteriores a este período.

\subsection{Pesquisa Documental}

Outro procedimento foi a pesquisa documental, por meio da observação, investigação e análise de documentos elaborados pela Emater-MG sobre o Projeto Transformar, bases de dados da juventude rural, além de questionário, levantamento e observação em reuniões com os jovens.

\subsubsection{Questionário de 2013}

Para coletar informações para a pesquisa, analisamos um questionário aplicado a 95 jovens de 16 a 29 anos, de ambos os sexos, de 22 municípios do Sul de Minas, participantes do Projeto Transformar e V SEJA (Semana do Jovem Agricultor) no IFSULDEMINAS/Campus Inconfidentes, em agosto de 2013. Utilizou-se desta análise como coleta de dados sobre a realidade da juventude rural do Sul de Minas, visando à caracterização do jovem e sua família e saber o que os jovens pensam sobre o futuro, na perspectiva dos atores sociais envolvidos.

Os questionários semiestruturados foram elaborados pela Pró-Reitoria de Extensão do IFSULDEMINAS, com questões abertas e fechadas divididas em 08 partes: Perfil do entrevistado; Composição Familiar; Educação; Lazer; Trabalho; Futuro; Organização Social; Meio Rural e Projeto Transformar e aplicados em quatro grupos de jovens, com monitores. 
Juventude rural e as contribuições do Projeto Transformar de capacitação de jovens rurais no sul de minas (2006-2013)

\subsubsection{Levantamento da situação dos egressos do Projeto}

\section{Transformar}

Com o objetivo de verificar a condição de permanência dos jovens egressos no meio rural, analisando o que modificou na vida dos jovens rurais, após terem participado do Projeto Transformar, realizamos um levantamento da situação dos 549 jovens participantes do Projeto Transformar, em 50 municípios das unidades regionais da Emater-MG de Alfenas e Lavras, de Setembro e Outubro de 2015, contando com o apoio dos extensionistas locais.

\subsubsection{Reunião com egressos e Não Participantes do Projeto}

\section{Transformar}

Buscamos a observação em reuniões organizadas pela Emater-MG com dois grupos de jovens rurais, o grupo participante do Projeto Transformar (egressos) e o grupo controle formado por jovens que não frequentaram o projeto (Não-Participantes), com faixa etária e escolaridade o mais próximo possível dos jovens participantes e da mesma comunidade rural, visando compreender a perspectiva dos próprios jovens rurais, a respeito de sua situação, de intenções de migrar ou permanecer (e as razões para estas intenções).

A escolha dos jovens foi baseada nos municípios que mais participaram do projeto e com maior representação (Lambari e Itamonte), identificando os jovens que permanecem no campo e com possibilidades de participarem das reuniões. Seguindo um roteiro de questões baseadas nas dimensões da sustentabilidade e na perspectiva de futuro, as reuniões foram realizadas em outubro de 2015 nas comunidades Congonhal/Lambari e Campo Redondo/Itamonte).

\section{Resultados e Discussão}

Esta seção está organizada numa análise da permanência dos jovens no meio rural e dos fatores que influenciam a migração ou permanência de jovens rurais no campo e a sucessão familiar, identificados na pesquisa bibliográfica. Focalizam as políticas públicas, em especial as de suporte à exploração produtiva da terra e busca-se compreender a perspectiva dos próprios jovens rurais, a respeito das intenções de migrar ou permanecer (e as razões para estas intenções).

\subsection{Permanência no meio rural e Sucessão familiar}

A pesquisa mostrou que a maioria dos jovens rurais do Sul de Minas tem a intenção de permanecer no campo e que este padrão é semelhante para todos os pesquisados. De acordo 
Juventude rural e as contribuições do Projeto Transformar de capacitação de jovens rurais no sul de minas (2006-2013)

com o Gráfico 1, quando questionados se pretendem continuar no meio rural, $80,4 \%$ dos 95 jovens participantes de 2013 responderam que sim e, entre os 19,6\% que manifestaram interesse em sair, os motivos são que as condições de trabalho, estudo, saúde e lazer são melhores nas cidades.

$\mathrm{Na}$ pesquisa com os egressos do Transformar, somando as duas unidades regionais (Alfenas e Lavras), com 50 municípios e 549 participantes, 344 jovens continuam no meio rural, ou seja, 62,66\%, o que corrobora com a pesquisa de Castro (2005b), em que a grande maioria dos jovens preferem ficar no campo, apesar das difíceis condições de vida e produção identificadas. A autora aponta que devemos olhar para os outros significados da saída dos "jovens", considerando a possibilidade de estarem "simplesmente" saindo da casa dos pais e construindo sua autonomia e que esta saída nem sempre é definitiva.

Ressaltamos que em dois municípios (Campo do Meio e Paraguaçu) nenhum dos 11 jovens participantes continua no meio rural, ao contrário do município de Elói Mendes, em que dos 19 participantes apenas 01 jovem saiu do meio rural. De acordo com as informações, 71 jovens mudaram do meio rural para trabalhar e 06 jovens saíram e depois retornaram para o meio rural. Dos jovens participantes, de 32 não obtiveram informações.

A maioria dos jovens do grupo Não Participantes gostaria de continuar os estudos, pois estão no ensino médio e se tiver que mudar para estudar, pretende voltar para a comunidade/município.

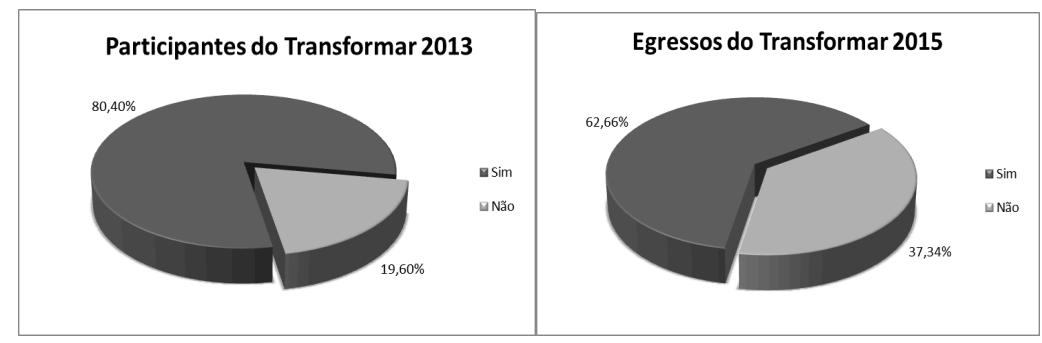

Gráfico 1: Percentual dos jovens participantes do Transformar 2013 que pretendem continuar no meio rural e egressos do Transformar (2015) que continuam no meio rural

Fonte: Dados da pesquisa.

Em oposição à permanência no meio rural, coloca-se o conceito de migração e na busca de referencial sobre migração da juventude rural, encontramos vários estudos que associam esta categoria ao problema da "migração do campo para a cidade", que vem ocorrendo desde 1940. 0 marco da discussão da tendência da migração do jovem rural para a cidade foi o trabalho de Camarano e Abramovay (1999) que analisaram as migrações rural-urbanas por sexo e idade nas décadas de 50, 60, 70, 80 e 90 e concluíram que a saída de agricultores do campo para as cidades incluíam pessoas cada vez mais jovens, com uma predominância crescente das mulheres. Desde a década de 1990, observaram-se mudanças na migração que passa a ocorrer a curtas e médias 
Juventude rural e as contribuições do Projeto Transformar de capacitação de jovens rurais no sul de minas (2006-2013)

distâncias e os fatores que estimularam as migrações foram o agronegócio, a proletarização do jovem rural e a falta de condições dos jovens desenvolverem projetos de vida.

Brumer (2007) mostra que os motivos para a migração rural são os fatores de atração (atrativos da vida urbana e trabalho remunerado) e os fatores de expulsão (dificuldades do meio rural e da atividade agrícola) e as decisões sobre a migração variam na avaliação destes fatores.

Em alguns países, a sucessão se dá, geralmente, ainda com os pais em vida e no Brasil ela se dá, usualmente, por um processo de herança. As questões relacionadas à sucessão não parecem objeto de uma preparação prévia e organizada, afetam todas as propriedades rurais e possui etapas que envolvem a definição sobre quem fica na propriedade, a forma de remunerar os não sucessores e a questão de gênero com a exclusão das filhas (MELLO et al., 2003).

\subsection{Fatores que podem influenciar a migração ou permanência dos jovens rurais no campo}

a) Questão de gênero

A questão do gênero é um fator a ser considerado e um atributo importante que modifica o desejo de permanência ou a capacidade de migração do jovem. De acordo com Brumer (2007), as moças deixam o meio rural em maior número, decorrente da desvalorização das atividades femininas no espaço rural e pela "invisibilidade de seu trabalho". o trabalho de Lima (2013) também identifica a dinâmica do não reconhecimento das moças como trabalhadoras e que a assimetria na distribuição de homens e mulheres torna mais difícil a formação de novas famílias.

De todos os 95 jovens participantes que responderam o questionário em 2013, 64,2\% são do gênero masculino e 35,8\% do gênero feminino e a maioria $(87,1 \%)$ com idade entre 16 a 24 anos e solteiros (97,9\%). Em oito anos do projeto, participaram 549 jovens das regionais de Alfenas e Lavras, sendo 70,13\% homens e 29,87\% mulheres. Interessante que, no município de Itamonte/Campo Redondo, todas as 09 jovens que participaram do projeto continuam no meio rural e também no grupo dos NP a maioria é de mulheres (62,50\%), o que corrobora com alguns estudos sobre a questão da masculinização do meio rural (Gráfico 2). Na análise dos 50 municípios pesquisados, em Aguanil, Baependi, Campanha, Campo Belo, Cordislândia, Divisa Nova, Pouso Alto, apenas os homens que participaram do projeto continuam no meio rural.

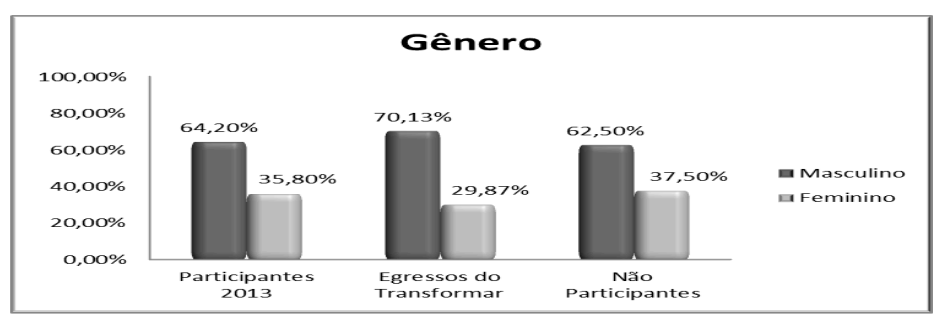


Juventude rural e as contribuições do Projeto Transformar de capacitação de jovens rurais no sul de minas (2006-2013)

Gráfico 2: Percentuais de jovens da pesquisa, segundo gênero

Fonte: Dados da pesquisa.

Os dados do IBGE (2010) evidenciam que há menos mulheres que homens no campo e trabalhando na agricultura e os homens são os responsáveis pela maior parte das casas. É preciso verificar em que condições as moças mostram interesse na agricultura, permitindo reverter a tradicional exclusão das mulheres da atividade agrícola (BRUMER, 2007).

\section{b) Estado civil}

Do grupo de 95 jovens que responderam ao questionário, 97,9\% estavam solteiros em 2013. Já, na pesquisa com os egressos, dos 344 jovens que continuam no meio rural a maioria está solteira $(75,87 \%)$, com $24,13 \%$ de jovens casados, destes últimos, 16 jovens casaram no Projeto Transformar, 05 jovens noivos e 02 namorados pelo projeto, entendendo que a convivência dos jovens durante o projeto contribui para a socialização e amizades.

\section{c) Escolaridade}

0 "acesso à educação e à formação profissional" é uma influência importante em relação à permanência no campo e o modelo de educação das cidades não se adapta à realidade rural, com um conteúdo direcionado para a realidade urbana, que não valoriza o rural e não prepara os jovens para um retorno ao campo (SOUZA, 2012).

Quanto à escolaridade dos jovens do questionário de 2013, constatamos que 44,7\% cursam o ensino médio e 29,8\% já concluíram e 5,3\% com ensino superior completo e/ou incompleto. Constatamos que a maioria dos 344 jovens egressos analisados, concluiu o ensino médio e dos 26 jovens do município de Itumirim, apenas um não concluiu o $2^{\circ}$ grau. Dos participantes que moram no meio rural, 6,40\% continuam seus estudos com curso superior de Agronomia (Machado e Varginha), Pedagogia EaD e outros. Um dos fatores importantes é que alguns jovens se formaram e estão ativos nas atividades rurais, sendo 08 como técnicos agropecuários, 02 agrônomos e 01 engenheiro mecânico, num retorno ao rural. Todos os jovens egressos (344) disseram já ter feito algum curso fora da escola (SENAR e Emater-MG).

Demonstrando o interesse pela educação, encontramos 25 jovens que estão fora de seus municípios para estudar em Universidades (Alfenas, Lavras, Machado, Três Corações, Varginha, Viçosa) ou Institutos Federais (Machado e Inconfidentes), sendo a maioria em cursos correlatos ao meio rural (Agronomia, Veterinária, Zootecnia, Técnico em Agropecuária, Administração).

Quando questionados se estão estudando, as jovens egressas de Itamonte estão cursando Pedagogia EaD e Educação Física e os jovens NP ainda estão no ensino médio e pretendem 
continuar os estudos. Já os jovens egressos de Lambari não continuaram os estudos pela falta de transporte, manutenção das estradas e distância.

Diversos autores (ABRAMOVAY et al., 2001; CASTRO, 2009; WEISHEIMER, 2005) comentam que os jovens rurais tem o acesso dificultado à escola, com a existência de escola próxima, distância das escolas urbanas e disponibilidade de transporte. A nucleação das escolas promovida nos últimos anos é considerada na pesquisa de Ferrari et al. (2004) uma das causas do afastamento dos jovens do meio rural, pois, nesse contexto, cresce a desvinculação com o meio rural e com ela aumenta também a possibilidade da migração definitiva do campo para a cidade.

Segundo dados do IBGE (2010), os jovens rurais vão à escola por menos tempo, as mulheres jovens do meio rural têm níveis de escolaridade mais altos, há um número maior de analfabetos de todas as idades na área rural e os jovens do campo estudam menos. Os dados são de que $80 \%$ dos jovens rurais precisam se deslocar para as cidades para ter acesso à educação formal e 22,8\% dos adolescentes do campo estão foram da escola. Outra análise é de que o trabalho na agricultura dificulta a educação dos jovens, principalmente para os homens.

d) Relação do jovem com o trabalho/Projeto produtivo

A demanda de renda própria é um dos fatores que podem facilitar ou dificultar a permanência dos jovens no meio rural. De acordo com Castro (2005a), outra inserção valorizada é o trabalho externo à propriedade, marcada por diferenças entre homens e mulheres e são vários objetivos desta saída como a manutenção da unidade de produção, o começo do processo de "saída" dos jovens e uma combinação de interesses pessoais e da família para atender seu consumo individual e de ajuda. A obtenção de recursos financeiros para atender às necessidades específicas do jovem pode resultar de partilha pela família, de economias possibilitadas por sua residência na casa paterna ou ainda de rendas obtidas fora da unidade produtiva (LIMA, 2013).

De acordo com o questionário, 65,3\% dos jovens fazem algo para ganhar dinheiro e, entre eles, 33\% ajudam os pais em sua propriedade, 53,1\% em atividades rurais (pecuária, agricultura, etc); $14,1 \%$ como trabalhador assalariado e 9,4\% com atividades domésticas na própria casa e com atividades na cidade (indústria, comércio, etc). Quanto aos jovens egressos, $62,5 \%$ tem renda própria, com uma maior proporção de atividades agrícolas, com 94 jovens ocupados com a cultura do café (sendo 06 jovens com café certificado Fair Trade em Boa Esperança); 44 na atividade leiteira; 18 com hortifrutigranjeiro; 07 com criação de codornas, trutas e abelhas; 14 jovens prestam serviços fora da propriedade como assalariados e 16 jovens trabalham com serviços de trator, motosserra e máquinas de café. 
Juventude rural e as contribuições do Projeto Transformar de capacitação de jovens rurais no sul de minas (2006-2013)

Considerando-se as transformações no meio rural com o surgimento do "Novo Rural"3, em que a pluriatividade na agricultura diversifica as possibilidades de inserção profissional dos jovens rurais (Schneider, 2006), as atividades não agrícolas já fazem parte da experiência cotidiana dos jovens que vivem no meio rural como agroindústria (05 jovens), artesanato (04 jovens) e turismo rural/pousadas em Itamonte e São Thomé das Letras (04 jovens)

Em relação aos projetos produtivos com renda própria do total analisado, constatamos que apenas 4,06\% dos jovens desenvolvem seus projetos, sendo uma experiência de horticultura com venda para o PNAE (Programa Nacional da Alimentação Escolar) e feira livre e os demais conduzem lavouras de café por conta própria ou em parceria, mostrando que a atividade cafeeira gera mais autonomia para os jovens rurais. Esta realidade não é diferente da relatada em diversas pesquisas que destacam as principais dificuldades dos jovens para implementarem seus projetos, como a falta de recursos financeiros e apoio/credibilidade dos pais, além de poucas opções de se construir uma renda na atividade agropecuária familiar.

A maioria dos jovens atualmente está fazendo alguma atividade para ganhar seu próprio dinheiro como produção de café (Lambari), ponkan, cogumelo e truta (Itamonte), leite e queijo. Também com serviços de faxineira, babá, professora, com transporte escolar, roçadeira e turismo rural/pousadas. A autonomia e "segurança" (salário e carteira assinada) do trabalho urbano aparecem como uma razão para o distanciamento e o desinteresse pelo trabalho na propriedade rural e com uma intensa circulação dos "jovens" em função do trabalho externo e da escola. Neste contexto, o trabalho urbano é valorizado pela renda "mais certa" que contribui com a renda da família e o estudo é mais associado a imagens de mobilidade social (CASTRO, 2005a).

\section{e) Relações familiares}

A maior parte dos jovens do questionário e egressos reside na propriedade rural com suas famílias e todos os jovens do grupo NP ainda moram com os pais. Alguns jovens residem na cidade/sede do município, mas estabelecem algum tipo de vínculo com a família/propriedade rural com visitas nos finais de semana e algum trabalho. Destaque para os jovens que continuam morando com os pais no meio rural e estudam na cidade, no ir e vir de todas as noites. Portanto todos os jovens mantêm relação direta com atividades rurais morando ou não na propriedade.

As relações entre os jovens e suas famílias são importantes, pois à medida que o jovem começa a ser valorizado pelo seu trabalho ou quando obtém um rendimento próprio para cobrir seus gastos pessoais, maior é a possibilidade de se manter no meio rural (WEISHEIMER, 2005).

\section{f) Participação Social}


Juventude rural e as contribuições do Projeto Transformar de capacitação de jovens rurais no sul de minas (2006-2013)

Sobre a participação social, as formas de organização/grupos na comunidade/bairro rural que os jovens participantes do Transformar em 2013 conhecem são Associação de Produtores (39,4\%), Cooperativa de Produtores Rurais (17,0\%), Associação/Conselho Comunitário $(10,6 \%)$ e 7,4\% não conhecem nenhuma forma de organização. Por meio das respostas, notamos que $46,3 \%$ dos jovens rurais participam de algum grupo, como grupo religioso (38,3\%), grupo de jovens (21,3\%) e com apenas 14,9\% participando de Associação de bairro (Gráfico 3).

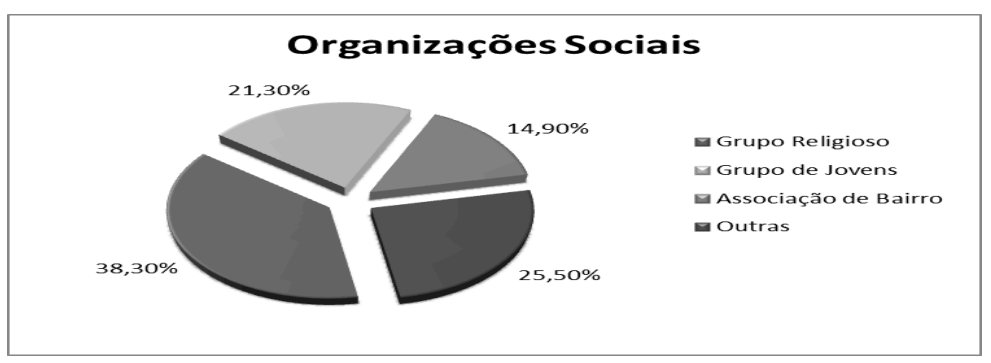

Gráfico 3 Percentual de participação dos jovens por organização social Fonte: Dados da pesquisa.

Quanto à participação em algum grupo da comunidade, os jovens egressos participam de grupo de jovens, da Associação e do Grupo do 3ํano (Campo Redondo/Itamonte) e os jovens NP não participam formalmente de nenhum grupo. Observa-se que existe maior envolvimento dos jovens pesquisados em eventos religiosos e depois maior participação nas atividades de lazer na comunidade. Estes dois espaços constituem-se em espaços de religiosidade e lazer dos jovens, onde as tomadas de decisão são menores, constituindo-se mais em espaços de socialização.

A participação social e envolvimento dos jovens rurais nas organizações existentes nas suas comunidades é pouco significativa e participam quando os pais não podem participar ou quando o assunto é mais abrangente e o convite é para toda família. Há um paradoxo, pois os jovens não participam por não terem espaço e não têm espaço porque não participam. É necessário um olhar diferenciado, pois eles serão os futuros proprietários e lideranças rurais.

\section{g) Beneficiários de Políticas Públicas}

As políticas públicas que beneficiam o jovem rural e sua família mais conhecidas dos entrevistados foram Bolsa Família; Pronaf (Programa Nacional de Fortalecimento da Agricultura Familiar); PSF (Programa Saúde da Família); Programa Luz para Todos e Projeto Transformar (jovens rurais). Em sequência, as respostas mostram que os jovens conhecem menos sobre o PNAE (Programa Nacional da Alimentação Escolar); PAA (Programa de Aquisição de Alimentos); Programa Minas Sem Fome e outras. 
Dentre os 344 egressos pesquisados, apenas 14 jovens $(4,2 \%)$ tiveram acesso ao crédito do Pronaf, nos municípios de Lambari (07 jovens), Boa Esperança (04 jovens), Lavras (02 jovens) e Itumirim (01 jovem), porém só 06 jovens conseguiram a linha específica Pronaf Jovem.

A política do Pronaf tem duas linhas de crédito que podem ser acessadas pelos jovens para custeio e investimentos na produção agrícola. A linha específica do Pronaf Jovem beneficia os filhos de famílias já enquadradas no Pronaf, para a atividade agrícola, em que o jovem rural explora parte da terra da família e, ainda, mora com ela. As outras linhas disponíveis do Pronaf podem ser acessadas por eles, se tiverem sido emancipados (LIMA, 2013).

As pesquisas analisadas sobre o tema relatam as muitas dificuldades que o jovem rural tem para ser financiado pelo Pronaf como: pouca divulgação; falta de informações; burocracia dos bancos com os jovens (risco de não pagar o empréstimo); falta de assistência técnica nos projetos de produção; dentre outras. É preciso qualificar o jovem, para que ele saiba os seus direitos, conheça os programas e como acessá-los e dialogar com os agentes financeiros.

Outra política pública do Ministério do Desenvolvimento Agrário (MDA), que beneficia os jovens rurais, é a Chamada Pública do Café e do Leite que iniciaram em 2014 e 2015, respectivamente, no Sul de Minas, beneficiando 08 jovens na atividade do café e 01 jovem no leite, inclusive como Unidade de Referência.

Dentre as políticas de comercialização da agricultura familiar no mercado institucional, 1,45\% dos jovens comercializam seus produtos no PNAE (Campanha, Elói Mendes, Itanhandu e Pouso Alto) e 0,58\% (02 jovens de Elói Mendes) comercializam no PAA/MDS em Varginha.

O Programa Minha Casa Minha Vida, voltado para o atendimento de demandas habitacionais rurais, beneficiou apenas 02 jovens em Boa Esperança, contribuindo para maior conforto da habitação e permanência dos jovens no campo.

Consideramos importante conhecer a visão dos entrevistados sobre o trabalho da ATER (assistência técnica e extensão rural pública). As respostas dos questionários mostram que 61,3\% dos jovens já foram atendidos pela Emater-MG, antes de participar do Projeto Transformar nas atividades de cursos (44,9\%); orientação técnica na sua propriedade $(34,8 \%)$ e palestras $(11,6 \%)$.

O vínculo dos jovens egressos de Lambari com a Emater-MG se dá por cursos, palestras e como beneficiários da Chamada Pública do Café do MDA recebem atendimento sistemático de 2014 a 2017, com visitas e acompanhamento técnico, participação em eventos (Dias de Campo, Circuito do Café e outros). Os jovens egressos e NP de Itamonte participam das atividades promovidas pela Emater-MG como Encontros de Mulheres, aulas de culinárias, palestras, visitas nas propriedades e capacitações com foco em educação ambiental e agroecologia. 
Juventude rural e as contribuições do Projeto Transformar de capacitação de jovens rurais no sul de minas (2006-2013)

A demanda por assistência técnica e extensão rural indica que as políticas de ATER têm muito a avançar, no sentido de atendê-la, seja em termos de cobertura (número de famílias atendidas), como no de qualidade da assistência fornecida. Para a maioria dos autores pesquisados, juventude rural não se apresenta como foco prioritário para as políticas públicas por ser percebida como "população minoritária". As políticas públicas de juventude deveriam ser elaboradas com a participação legítima do jovem como ator social, considerando suas demandas específicas, a diversidade e especificidades de ser jovem no meio rural brasileiro.

\subsection{Perspectivas dos jovens rurais do Sul de Minas}

Explorando a perspectiva do jovem com relação ao seu futuro, a pesquisa evidenciou o dilema em relação ao "ficar na propriedade" e ao "sair da propriedade", que é mais complexo que a leitura da atração pela cidade. No que se refere aos planos para o futuro, $51,1 \%$ dos jovens participantes do Transformar em 2013 manifestaram a intenção de cursar uma faculdade; $39,4 \%$ de possuir a própria terra e apenas $2,1 \%$ de mudar para a cidade.

Nas reuniões com os jovens egressos e os NP, quando perguntados sobre os planos para o futuro, a maioria dos jovens de Itamonte gostaria de continuar os estudos e se tiver que mudar da comunidade e município para estudar, pretende retornar depois. Já os jovens de Lambari pretendem continuar na atividade rural pelas razões de não ter patrão, ter pouco estudo e por falta de opção. A ideia dos jovens é melhorar a qualidade do seu café para exportação.

Visando aprofundar a questão da perspectiva de futuro, os jovens foram questionados sobre o que gostariam que tivesse no campo, para continuarem a viver lá: oportunidades de emprego (renda própria); condições de acesso ao ensino sem abandonar suas atividades, com mais opções e facilidades; mais acesso aos serviços sociais (saúde, lazer, cultura) e estradas melhores; maior valorização do trabalho no campo com acesso à própria terra (Gráfico 4).

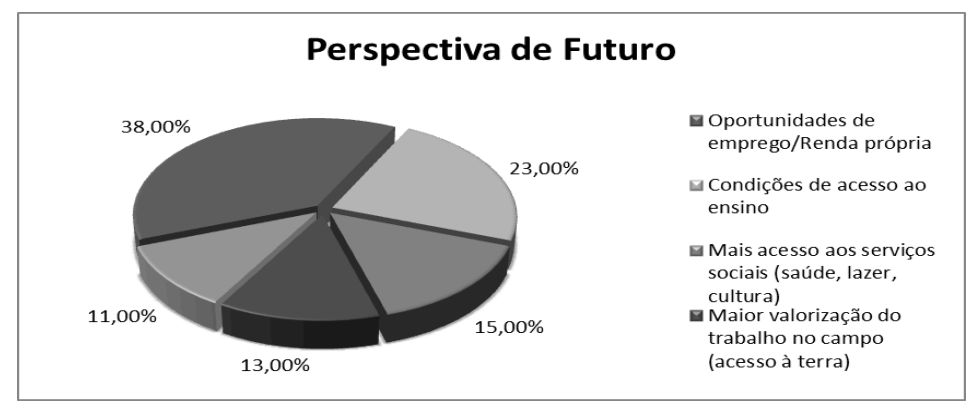

Gráfico 4: Perspectiva de futuro dos jovens rurais participantes, egressos do Projeto Transformar e NP Fonte: Elaborado pela autora por meio de pesquisa junto aos jovens rurais, realizada em 2013 e 2015. 
Juventude rural e as contribuições do Projeto Transformar de capacitação de jovens rurais no sul de minas (2006-2013)

Além do ensino precário, a dependência econômica, o esforço físico da atividade agrícola, a falta de oportunidades de trabalho e acesso ao crédito e tecnologias, as dificuldades para acesso à internet e à comunicação de qualidade, as limitadas opções de lazer, têm impulsionado a migração dos jovens para as cidades. Estes acabam pensando que terá acesso a tudo isto na cidade, sem perceber que pela sua formação e qualificação terá dificuldade de se incluir na sociedade urbana.

\section{Considerações Finais}

Com esta pesquisa, já se pôde levantar algumas características do jovem rural do Sul de Minas, confirmando o senso comum relacionado ao jovem rural. 0 perfil trouxe uma diversidade de elementos para entendermos quem é esse jovem rural do Sul de Minas, seus sonhos e preocupações, evidenciando uma juventude que luta pelo trabalho, renda, terra, educação, lazer e cultura em um campo sem acesso a bens e serviços.

Em relação à permanência no meio rural, os resultados indicaram que a maioria dos jovens tem grande interesse em continuar vivendo no meio rural pelo gosto de morar no campo e pretende dar continuidade à atividade agrícola; mesmo se formarem profissionalmente em outras áreas querem continuar mantendo relações com o campo. Existe um desejo maior de permanecer no meio rural por parte dos rapazes e, se não o fazem, é porque não encontram condições favoráveis e dignas de permanência. Entende-se que o Projeto Transformar fortaleceu este desejo, mostrando alternativas de atividades produtivas viáveis no meio rural, para que os jovens possam obter ocupação profissional e renda, com maiores oportunidades.

Para conseguir melhorar as condições de vida do jovem, é preciso conhecer por que os jovens deixam suas comunidades rurais, o que estariam esperando encontrar nas cidades e o que deveria ser feito, dando-lhe oportunidades no campo. As demandas dos jovens rurais são diferenciadas por região e gênero e as migrações acontecem, quando essas demandas não são atendidas e o jovem não vê oportunidades futuras no campo. A cobrança da permanência dos jovens no campo como valorização e reversão do quadro de esvaziamento do meio rural implica esforço de sair do discurso do jovem como herói da transformação social e ir para ações práticas.

A limitação da renda obtida pela família nas atividades agropecuárias, a falta de renda própria e de mais ensino no campo levam os jovens a optar por sair da propriedade, em busca de novas oportunidades. Os jovens têm o desejo de obtenção de uma renda que lhes permitam satisfazer suas próprias necessidades e desejos, sem a determinação do pai de como será usado o dinheiro da produção que o jovem participou. Os sistemas de produção adotados na unidade familiar podem favorecer mais ou menos a participação dos jovens, os processos de decisão e provocar alterações na maneira de se fazer a gestão da propriedade. Isto pode ser percebido, 
especialmente, na atividade da cafeicultura em que o jovem consegue um talhão ou desenvolve parcerias, favorecendo seu acesso à renda.

A análise dos resultados permite verificar que parte dos jovens do Sul de Minas valoriza a educação, almejam a conquista de maiores níveis de escolaridade e gostaria de conciliar o estudo com a manutenção da residência no meio rural junto aos pais, indicando que ocorre uma forte relação ao modo de vida rural. A maioria dos jovens concluiu o ensino médio e pretende continuar os estudos, o que mostra a importância de se ampliar de forma efetiva e com qualidade os investimentos em educação no meio rural. Há diferenças entre os jovens na valorização da educação: as moças investem mais na educação que os rapazes. Verifica-se uma parcela de jovens que efetivamente está buscando uma qualificação profissional para aprimorar a profissão de agricultor ou formação para outra atividade profissional. É necessário que se busquem alternativas e parcerias para aumentar a qualificação e a formação do jovem rural, em especial sobre a gestão da propriedade e do negócio, com a intensificação e aperfeiçoamento da capacitação de jovens rurais, compatíveis com a atividade de produção rural.

Alguns estudos vêm mostrando a mudança nos padrões sucessórios e a socialização de experiências bem sucedidas de sucessão enquanto os pais ainda são relativamente jovens. Quanto às formas de preparo do futuro agricultor nas propriedades, a maioria apenas acompanha as atividades do dia a dia da propriedade e consideramos que muitos deles não estão sendo preparados para assumir um projeto produtivo próprio. Os agricultores familiares e suas organizações representativas não parecem preparados para enfrentar os novos desafios dos processos sucessórios, o que se torna mais difícil com a escassez de terras (fracionamento das propriedades da agricultura familiar) e, também, com as moças à margem deste processo.

Outro tema destacado na pesquisa foi o baixo índice de participação dos jovens nas organizações sociais. Os jovens enfrentam tensões nos espaços de decisão na família e nas comunidades, carregando limitações quanto ao espaço de participação, à possibilidade de ser ouvido e à dificuldade de poder se colocar em um espaço de decisão. Esta não valorização aparenta uma falsa imagem de que o jovem não tem interesse em participar das decisões.

As avaliações de políticas públicas das pesquisas analisadas indicam a insuficiência de acesso a essas políticas por parte dos jovens rurais, como é o caso do Pronaf Jovem e outras. Os diferentes trabalhos referenciados apontam no sentido da necessidade de desenvolvimento de políticas públicas específicas para os jovens rurais. E mesmo readequações das políticas públicas para a juventude rural além de que os processos de formulação tenham a participação da juventude como ator social e político formulador e não apenas população alvo.

O jovem não tem conseguido acessar o crédito rural (Pronaf Jovem), que é o suporte financeiro para a produção. É urgente que os governos adotem políticas de incentivo, 
direcionem e busquem o aperfeiçoamento das linhas de créditos para estimular os jovens a se dedicar a atividades que maximizassem a utilização de recursos como mão de obra e rentabilidade por área, como a horticultura, fruticultura, criação de pequenos animais e pecuária leiteira.

O programa de assistência técnica e extensão rural (ATER) têm seus valores de financiamento reduzidos para suas atividades e com isto, a ATER tem sido oferecida de forma incipiente e insuficiente. Embora se reconheçam suas limitações nos projetos atuais, com falta de técnicos em quantidade e capacitação adequada, para atender especificamente ao público jovem. Considera-se a necessidade de uma proposta de ATER, que inclua esta categoria social em todas as etapas, que atenda às necessidades e demandas dos jovens rurais, mostrando que ele pode ser um empreendedor, para desenvolver seu projeto, pela sua motivação, talento, iniciativa, força de vontade e conhecimentos. 0 jovem rural deveria ser considerado como grupo social a merecer atenção especial da ATER, atribuindo prioridade ao trabalho com a juventude, mantendo contatos e criando atividades de extensão estimulantes para ela como grupos de jovens ou projetos/programas específicos em seu benefício, como o Projeto Transformar.

Diante dos dados apresentados nesta pesquisa, é notória a necessidade de elaboração de políticas públicas mais eficazes e divulgadas que garantam aos jovens o acesso à educação, qualificação profissional, saúde de boa qualidade, melhores condições de trabalho no campo (acesso a terra, crédito, tecnologia e assistência técnica), instituições de formação profissional direcionada ao campo (escolas agrícolas) e infraestrutura para lazer e cultura.

Referenciando Brumer (2007), que propõe não apenas responder à questão 'porque os jovens saem do meio rural' e, sim, buscar respostas à questão 'porque os jovens permanecem no meio rural', analisando os aspectos que favorecem os jovens como agricultores e os motivos de fracasso na sucessão geracional dos estabelecimentos, incluindo a perspectiva de gênero.

Frente aos objetivos propostos por esta pesquisa e resultados encontrados, analisa-se que o Projeto Transformar trouxe diversas contribuições e atendeu aos jovens interessados em trabalhar e permanecer no campo, estimulando o desenvolvimento e inserção socioeconômica. Pela participação, empolgação, relatos, perspectivas e desenvolvimento das atividades dos jovens em suas propriedades, percebem-se algumas mudanças de caráter social, ambiental e econômico. Juntamente com os extensionistas, constata-se que o processo seletivo bem feito dos jovens, principalmente aqueles de famílias acompanhadas pela extensão, foi essencial para a receptividade, maturidade e comprometimento dos jovens participantes. Considera-se imprescindível a oferta de programas e projetos de capacitações como a proposta do Transformar, reformulados de acordo com as especificidades de cada região e avaliações dos envolvidos. 
O proposto por este estudo foi descrito ao longo desta pesquisa, mas ainda há muito para se estudar e conhecer da realidade dos jovens rurais do Sul de Minas, devido à complexidade, particularidades e abrangência da região. Esta pesquisa não pretendeu ser exaustiva, cabendo uma análise mais aprofundada e requer uma pesquisa de campo com uma amostra bem maior para responder às questões se os jovens estão mais integrados à comunidade, mais interessados pelo trabalho e família, introduzem novas técnicas na propriedade e estão preparados para a sucessão.

Como observado na análise das reuniões, os jovens egressos apresentaram os mesmos indicadores em todos os aspectos pesquisados, se relacionados aos jovens Não Participantes. Acredita-se que, por serem da mesma comunidade, a amostra não proporcionou um comparativo ideal, o que requer um aprofundamento maior e amostras com jovens de outras comunidades.

Espera-se com este estudo ter contribuído para o aprofundamento do olhar sobre os jovens rurais do Sul de Minas, demonstrando o que é ser jovem no mundo de hoje. Compreendendo as necessidades e especificidades da juventude rural, criando e/ou ampliando ações e políticas públicas adequadas, que, de fato, insiram e promovam os jovens, contribuindo para o fortalecimento da agricultura familiar e o desenvolvimento rural sustentável. Pode-se afirmar que a juventude rural apresenta-se como um potencial a ser considerado, quando se pensa na formação de uma nova geração de agricultores, pois estão abertos às transformações e podem atuar como protagonistas no processo de desenvolvimento da agricultura familiar no Brasil.

\section{Referências}

ABRAMOVAY, R. et al. Agricultura familiar e sucessão profissional: novos desafios. Brasília: NEAD/MDA, 2001. 122 p.

BRUMER, A. A problemática dos jovens rurais na pós-modernidade. In: CARNEIRO, M. J.; CASTRO, E. G.(Ed.). Juventude rural em perspectiva. Rio de Janeiro:Mauad X, 2007.p.35-51.

BRUMER, A.; PANDOLFO, G. C.; CORADINI, L. Gênero e agricultura familiar: projetos de jovens filhos de agricultores familiares na Região Sul do Brasil: fazendo gênero: corpo, violência e poder. Porto Alegre: UFRGS, 2008.7 p.

CAMARANO, A. A.; ABRAMOVAY, R. Êxodo rural, envelhecimento e masculinização no Brasil: panorama dos últimos 50 anos. Rio de Janeiro: IPEA, 1999. 28 p. (IPEA Texto, 621).

CASTRO, E. G. Juventude rural: "apenas uma palavra" ou "mais que uma palavra". In: ENCONTRO ANUAL DA ASSOCIAÇÃO NACIONAL DE PÓS-GRADUAÇÃO E PESQUISA EM CIÊNCIAS SOCIAIS, 29, 2005, Caxambu. Anais... Caxambu: ANPOCS, 2005a. p. 1-15. 
CASTRO, E. G. Processo de construção da categoria juventude rural como ator político: participação, organização e identidade social. In: REUNIÃO BRASILEIRA DE ANTROPOLOGIA, 26, 2005, Porto Seguro. Anais... Porto Seguro: GT10, 2005b. 1 CD-ROM.

CASTRO, E. G. Juventude Rural no Brasil: processos de exclusão e a construção de um ator político. Revista Latinoamericana de Ciencias Sociales, Niñez y Juventud, Manizales, v. 7, n. 1, p. 179-208, 2009.

EMPRESA DE ASSISTÊNCIA TÉCNICA E EXTENSÃO RURAL DO ESTADO DE MINAS GERAIS. Projeto básico Transformar. Belo Horizonte, 2007.16 p.

EMPRESA DE ASSISTÊNCIA TÉCNICA E EXTENSÃO RURAL DO ESTADO DE MINAS GERAIS. Projeto Transformar: casos de sucessos dos jovens rurais mineiros. Belo Horizonte, 2010. 104 p.

FERRARI, D. L. F. et al. Dilemas e estratégias dos jovens rurais: ficar ou partir? Estudos Sociedade e Agricultura, Rio de Janeiro, v. 12, n. 2, p. 237-271, 2004.

GIL, A. C. Métodos e técnicas de pesquisa social. 6. ed. São Paulo: Atlas, 2008. 220 p.

INSTITUTO BRASILEIRO DE GEOGRAFIA E ESTATÍSTICA. Censo demográfico 2010: universo, características da população e dos domicílios. Rio de Janeiro, 2010. Disponível em: <http://www.sidra.ibge.gov.br/cd/cd2010u-niverso.asp?o=5\&i=P>. Acesso em: 10 nov. 2014.

INSTITUTO FEDERAL DO SUL DE MINAS. Campus Inconfidentes. Questionário SEJA. Inconfidentes, 2013.

LIMA, S. M. V. Juventude rural e as políticas e programas de acesso à terra no Brasil: recomendações para políticas de desenvolvimento para o jovem Rural. Brasília: MDA, 2013. 184 p. (NEAD Estudos, 25).

MELLO, M. A. de et al. Sucessão hereditária e reprodução social da agricultura familiar. Agricultura em São Paulo, São Paulo, v. 50, n. 1, p. 11-24, 2003.

SCHNEIDER, S. A pluriatividade no meio rural brasileiro: características e perspectivas para investigação. Porto Alegre: UFRGS, 2006. 29 p.

SOUZA, A. C. Juventude e educação do campo no município de Alfenas, MG. In: ENCONTRO NACIONAL DE GEOGRAFIA AGRÁRIA, 21, 2012, Uberlândia. Anais... Uberlândia: UFU, 2012.

SPANEVELLO, R. M. et al. A migração juvenil e implicações sucessórias na agricultura familiar. Revista de Ciências Humanas, Florianópolis, v. 45, n. 2, p. 291-304, out. 2011.

WEISHEIMER, N. Juventudes rurais: mapa de estudos recentes. Brasília: Ministério do Desenvolvimento Agrário, 2005. 76 p. (Estudos Nead, 7). 
Rural youth and contributions of the Project Transform of Training Young People in the south of mines (2006-2013)

\begin{abstract}
One of the main challenges for the rural environment is the continuity of the production of food and the formation of a new generation of farmers, given that the young abandon the property. The intent of this study was to analyze de results obtained from the Transform Rural Youth Training Project for keeping the young in the countryside and in family succession in Southern Minas Gerais, Brazil. The technical assistance and rural extension company in the state of Minas Gerais (Emater-MG), implemented the project "Transform", encompassing the rural youth of between. We combined qualitative and quantitative studies, the result analysis allowed us to verify that most rural young from Southern Minas Gerais like to live in the countryside and intend to continue farming activities, but found difficulties in accommodating work and studies and obtaining their own income. The study allowed us to seeking to understand the reality in which rural young from Southern Minas Gerais live in and showed that project "Transform" brought several contribution in stimulating the development and socioeconomic insertion of rural young and their permanence in the countryside and we present a few proposals and reflections to subsidize the establishment of new work strategies.
\end{abstract}

\section{Keywords}

Rural youth. Migration. Family succession. Public policies.Project Transform.
Juventud rural y las contribuciones del Proyecto Transformar de Capacitación de Jóvenes Rurales en el sur de minas (20062013)

\section{Resumen}

Uno de los grandes desafíos del medio rural es la continuidad de la producción de alimentos y la formación de una nueva generación de agricultores, a medida que los hijos abandonan la propiedad. El propósito de este estudio fue analizar los resultados del Proyecto Transformar de Capacitación de Jóvenes Rurales, para la permanencia de los jóvenes en el campo y en la sucesión familiar, en el Sur de Minas. La Empresa de Asistencia Técnica y Extensión Rural del Estado de Minas Gerais (Emater-MG) ejecutó, en el período de 2006 a 2013, el Proyecto "TRANSFORMAR", orientado a la Juventud Rural. En la búsqueda de la combinación de estudios cualitativos y cuantitativos, el análisis de los resultados de la investigación permitió verificar que gran parte de los jóvenes rurales del Sur de Minas gusta de vivir en el campo y pretende dar continuidad a la actividad agrícola, pero encuentra dificultades para conciliar trabajo y estudio y obtener dificultades la renta propia. El estudio posibilitó conocer la realidad en que viven los jóvenes rurales del Sur de Minas, mostró que el Proyecto Transformar trajo varias contribuciones para estimular el desarrollo e inserción socioeconómica de los jóvenes rurales y su permanencia en el campo y presentó algunas propuestas y reflexiones para subsidiar el establecimiento de nuevas estrategias de trabajo con la juventud rural.

\section{Palavra clave}

Juventud rural. Migración. Sucesión familiar. Políticas Públicas. Proyecto Transformar.

Original submetido em: 4 maio 2016

Aceito para publicação em: 17 nov. 2016

Sobre a autora:

Flora Teixeira Castro

Professora do Departamento de Administração e Economia - Universidade Federal de Lavras, Minas Gerais - Brasil. 